\title{
RESPOSTA DO FEIJÃO CAUPI A SALINIDADE DA ÁGUA DE IRRIGAÇÃO
}

\author{
Carlos José Gonçalves de Souza Lima \\ Graduando em Engenharia Agronômica, Bolsista PIBIC/CNPq, Dept ${ }^{\circ}$. Ciências Ambientais UFERSA, Mossoró - RN. \\ E-mail:kj.gon@bol.com.br \\ Francisco de Assis de Oliveira \\ Eng ${ }^{\circ}$ Agr $^{\circ}$, Pós-graduando em Irrigação e Drenagem, Bolsista CAPES, UFERSA, Mossoró - RN \\ E-mail: thikaoamigao@bol.com.br \\ José Francismar de Medeiros \\ Eng $^{\circ}$ Agr $^{\circ}$, Dr., Bolsista CNPq, Dept ${ }^{\circ}$. Ciências Ambientais, UFERSA, Mossoró - RN \\ E-mail: jfmedeir@ufersa.edu.br \\ Mychelle Karla Teixeira Oliveira \\ Graduanda em Engenharia Agronômica, Bolsista PIBIC/CNPq, Deptº . Ciências Ambientais, UFERSA, Mossoró - RN. \\ E-mail: mychellekarla.oliveira@bol.com.br \\ Agenor Bezerra de Almeida Júnior \\ Eng $^{\circ}$ Agr $^{\circ}$ Dept $^{\circ}$. Ciências Ambientais, UFERSA, Mossoró - RN. \\ E-mail: kj.gon@bol.com.br
}

\begin{abstract}
RESUMO - Este trabalho foi realizado com o objetivo de avaliar o efeito de diferentes níveis de salinidade da água de irrigação no desenvolvimento de plantas de caupi. O delineamento utilizado foi o inteiramente casualizado com cinco tratamentos $\left(0,5 ; 2,13 ; 2,94 ; 3,5\right.$ e $\left.5,0 \mathrm{dS}^{-1}\right)$ e três repetições. As plantas foram coletadas aos 45 dias após semeadura, sendo avaliadas: o diâmetro do caule, número de nódulos nas raízes, altura, número de folhas, área foliar, matéria seca da raiz, da parte aérea e matéria seca total. A salinidade influenciou linearmente no crescimento vegetativo do feijão caupi, sendo todas as características analisadas reduzidas com o aumento da salinidade. As características mais afetadas pelo maior nível salino foram: área foliar (65,90\%), matéria seca da parte aérea $(66,94 \%)$ e matéria seca das raízes (76,14\%). A presença de nódulos nas raízes foi afetada drasticamente pela salinidade, com uma redução de 98,71\% no maior nível. A matéria seca total acumulada pelas plantas de caupi é distribuída em 22,5\% para a matéria seca das raízes e $77,5 \%$ da matéria seca da parte aérea, desta, $61,2 \%$ e 38,8\% são distribuídas para matéria seca das folhas e do caule, respectivamente.
\end{abstract}

Palavras chave: Vigna unguiculata, estresse salino, água salina

\section{ANSWER OF THE COWPEA THE SALINITY OF THE WATER OF IRRIGATION}

\begin{abstract}
This work was accomplished with the objective of evaluating the effect of different levels of salinity of the irrigation water in the development of cowpea. The used design was it entirely randomized with five treatments $(0.5$, 2.13, 2.94, 3.5 and $5.0 \mathrm{dS} \mathrm{m}^{-1}$ ) and three replications. The plants were collected to the 45 days after sowing, being appraised: the diameter of the stem, number of nodules in the roots, height, number of leaves, leaf area, matter dries of the root, of the aerial part and matter total drought. The salinity influenced lineally in the vegetative growth of the cowpea, being all the characteristics analyzed reduced with the increase of the salinity. The most affected characteristics for the largest saline level were leaf area (65.90\%), matter dries of the aerial part (66.94\%) and matter dries of the roots (76.14\%). The presence of nodules in the roots went affect drastically for the salinity, with a reduction of $98.71 \%$ in the largest level. The matter total drought accumulated by the caupi plants is distributed in $22.5 \%$ for the matter dries of the roots and $77.5 \%$ of the matter dries of the aerial part, of this, $61.2 \%$ and $38.8 \%$ are distributed for matter dries of the leaves and of the stem, respectively.
\end{abstract}

Key Word: Vigna unguiculata, salt stress, saline water 


\section{REVISTA VERDE DE AGROECOLOGIA E DESENVOLVIMENTO SUSTENTÁVEL GRUPO VERDE DE AGRICULTURA ALTERNATIVA (GVAA)}

\section{INTRODUÇÃO}

O feijão caupi, também conhecido como feijão-decorda ou feijão-macassar, constitui-se na principal cultura de subsistência das regiões Norte e Nordeste do Brasil, especialmente no Sertão Nordestino. A área cultivada com caupi no Brasil é, de aproximadamente 1 milhão de hectares, dos quais cerca de 900 mil (90\%) estão situados na região Nordeste do Brasil. Essa cultura apresenta grande importância na alimentação das populações que vivem nessas regiões, principalmente as mais carentes, pois fornece um alimento de alto valor nutritivo, sendo um dos principais componentes da dieta alimentar, gerando também emprego e renda, tanto na zona rural quanto na zona urbana.

Por ser uma cultura tipicamente de subsistência, a maioria dos produtores são considerados pequenos ou médios, com produção destinada primeiramente para consumo doméstico, e venda da produção excedente. Como os pequenos produtores não possuem infraestrutura para uma produção mais tecnificada, grande parte desses produtores cultiva o caupi na estação das chuvas.

A irrigação é uma das tecnologias aplicadas na agricultura que mais tem contribuído para o aumento na produção de alimentos, no entanto esta prática deve ser usada de forma racional, uma vez que as condições de clima do Nordeste (altas temperaturas, baixa pluviosidade e os elevados teores de sais nas águas de irrigação), vêm causado problemas de salinização nos solos. A crescente necessidade de se aumentar à produção de alimentos, tem aumentado significativamente a expansão das áreas cultivadas, porém essa busca não leva em conta apenas à expansão das áreas agrícolas, mas também, do uso de águas consideradas de qualidade inferior, bem como a reutilização de água de drenagem com elevados teores de sais e a utilização de espécies capazes de apresentar elevada rentabilidade quando irrigadas com esses tipos de água (RHOADES et al., 2000). De acordo com Medeiros \& Gheyi (1997) o nível de salinidade dos solos deve ser sempre inferior ao nível nocivo às plantas cultivadas. No Nordeste brasileiro, as águas utilizadas na irrigação apresentam, na maioria das vezes, concentração de sais na faixa de 1 a $30 \mathrm{mmol}_{\mathrm{c}} \mathrm{L}^{-1}$ correspondendo à faixa de condutividade elétrica de 0,1 a 3,0 dS m$~^{-1}$ (HOLANDA \& AMORIM, 1997).

De acordo com os dados obtidos pela FAO, o feijão-de-corda tolera a irrigação com água salina com condutividade elétrica de até $3,3 \mathrm{dS} \mathrm{m}^{-1}$ (AYERS \& WESTCOT, 1999), sendo considerada então como uma espécie moderadamente tolerante à salinidade, no entanto, Dantas et al. (2002) afirmam que o grau de tolerância do caupi ao estresse salino varia entre genótipos.

Objetivou-se, portanto, com este trabalho, avaliar o crescimento vegetativo e a partição de fotoassimilados de feijão caupi irrigado com águas de diferentes níveis de salinidade.

\section{MATERIAL E MÉTODOS}

O experimento foi conduzido em casa de vegetação, no Departamento de Ciências Vegetais da Universidade Federal Rural do Semi-Árido (UFERSA), localizada nas coordenadas geográficas de $5^{\circ} 11^{\prime} 31$ ”de latitude sul e $37^{\circ} 20^{\prime} 40^{\prime \prime}$ de longitude oeste de Greenwich, com altitude média de $18 \mathrm{~m}$. O clima da região, na classificação de Koeppen, é do tipo BSwh', (quente e seco), com precipitação pluviométrica bastante irregular, média anual de 673,9 mm; temperatura média de $27^{\circ} \mathrm{C}$ e umidade relativa do ar média de 68,9\% (CARMO FILHO \& OLIVEIRA, 1995).

Utilizou-se o delineamento inteiramente casualizados, com cinco tratamentos e três repetições. Os tratamentos foram constituídos de diferentes níveis de salinidade da água de irrigação (0,5; 2,13; 2,94; 3,5 e 5,0 $\mathrm{dS} \mathrm{m}^{-1}$ ), sendo cada unidade experimental representada por uma planta/vaso, com capacidade de $2,5 \mathrm{dm}^{3}$. Como substrato foi utilizada amostra da camada de $0-20 \mathrm{~cm}$ de um Argissolo Vermelho Amarelo de textura arenosa. O solo foi tamizado em malha de $2,0 \mathrm{~mm}$ e analisado quimicamente, apresentando as seguintes características: $\mathrm{pH}=6,9 ; \mathrm{CE}=0,7 \mathrm{dS} \mathrm{m}{ }^{-1} ; \mathrm{Ca}^{2+}=4,1 ; \mathrm{Mg}^{2+}=2,0 ; \mathrm{K}^{+}=0,27$; $\mathrm{Na}^{+}=0,11 ; \mathrm{Al}^{-3}=0,05 ; \mathrm{cmol}_{\mathrm{c}} \mathrm{dm}^{-3}$ e $\mathrm{P}=35,61 \mathrm{mg} \mathrm{\textrm {dm } ^ { - 3 }}$. Foram semeadas em cada vasos cinco sementes, da cultivar 'Quarentinha', sendo realizado o desbaste aos 6 dias após a semeadura, deixando-se as duas plantas mais vigorosas. A cultivar foi escolhida por apresentar crescimento determinado e ciclo precoce, além da ausência de estudos com este genótipo.

As irrigações foram realizadas diariamente com água proveniente da rede de abastecimento do campus da UFERSA, até ser efetuado o desbaste, quando a partir deste, a água utilizada na irrigação apresentava diferentes níveis de salinidade, de acordo com os tratamentos estudados. Os níveis de salinidades avaliados foram obtidos pela mistura de duas fontes de água, apresentando as condutividades elétricas de 0,5 e $5,0 \mathrm{dS} \mathrm{m} \mathrm{m}^{-1}$, provenientes de poços localizados no campus da UFERSA. As proporções corresponderam a 1:0, 1:2, 1:1, $1: 2$ e $0: 1$, para as águas das fontes 1 e 2 respectivamente

As plantas foram coletadas aos 45 dias após a semeadura, época mais adequada para estudo da nodulação (VASCONCELOS et al., 1976), transportadas para o laboratório de Irrigação e Drenagem do Departamento de Ciências Ambientais da UFERSA, onde foram seccionadas em caule, folha e raízes. As variáveis analisadas foram: número de folhas (NF), área foliar (AF), diâmetro do caule (DC), altura (ALT), número de nódulos (NOD), matéria seca da parte aérea (MSPA) e do sistema radicular (MSR) e matéria seca total (MST). Para o número de folhas foram consideradas apenas as folhas ativas, na determinação da área foliar foi utilizando o integrador de área foliar, modelo LI-3100 da Licor. O diâmetro do caule foi medido utilizando um paquímetro e a altura $(\mathrm{cm})$ com uma régua graduada. Para determinação da matéria seca da parte aérea e do sistema radicular (g) 


\section{REVISTA VERDE DE AGROECOLOGIA E DESENVOLVIMENTO SUSTENTÁVEL GRUPO VERDE DE AGRICULTURA ALTERNATIVA (GVAA)}

as plantas foram acondicionadas em sacos de papel e postas para secar em estufa de circulação forçada de ar, à temperatura de $70{ }^{\circ} \mathrm{C} \pm 1{ }^{\circ} \mathrm{C}$, até atingir peso constante, em seguidas foram pesadas em balança analítica de precisão $0,01 \mathrm{~g}$. No final do experimento foram coletadas amostras de solo de cada tratamento com o objetivo de avaliar a influencia da irrigação com água salina na condutividade elétrica do solo. A condutividade elétrica do extrato de saturação do solo foi estimada a partir da $\mathrm{CE}_{1: 2}$, que é medida no sobrenadante obtido numa mistura de 1 parte de solo para 2 de água. Para estimar a CEes a partir da $\mathrm{CE}_{1: 2}$ foi utilizada uma equação de regressão encontrada por Medeiros et al. (2002), conforme a seguinte equação: $\mathrm{CE}_{\mathrm{es}}=2,83 \mathrm{CE}_{1: 2}$. Os resultados obtidos foram submetidos às análises de variância e, por serem oriundos tratamentos com variáveis quantitativas foram submetidos à análise de regressão.

\section{RESULTADOS E DISCUSSÃO}

Foi encontrada resposta significativa $(\mathrm{p}<0,01)$ em todas as variáveis avaliadas, de forma que os níveis salinos da água de irrigação exerceram influência forte no desenvolvimento das plantas de caupi (Tabela 1). Souza et al. (2007), trabalhando com salinidade no desenvolvimento de caupi, e Santana et al. (2003) trabalhando com feijoeiro comum (Phaseolus vulgaris L.), também encontraram resposta significativa em todas as características avaliadas.

Tabela 1. Resumo da análise de variância para número de folhas (NF), área foliar (AF), altura (ALT), diâmetro do caule (DC), número de nódulos (NOD), matéria seca da parte aérea (MSPA), da raiz (MSR) e total (MST) de plantas de feijão caupi irrigada com água de diferentes salinidades. Mossoró-RN. UFERSA, 2007.

\begin{tabular}{ccccccccc}
\hline \multirow{2}{*}{$\begin{array}{c}\text { Fonte de } \\
\text { Variação }\end{array}$} & NF & AF & ALT & DC & NOD & MSPA & MSR & MST \\
\hline Salinidade & $17,23^{* *}$ & $40330,15^{* *}$ & $38,71^{* *}$ & $1,55^{* *}$ & $319,28^{* *}$ & $1,71^{* *}$ & $0,23 * *$ & $3,17^{* *}$ \\
Resíduo & 1,27 & 1852,91 & 2,56 & 0,26 & 9,38 & 0,08 & 0,03 & 0,15 \\
Media geral & 9,42 & 321,38 & 16,13 & 10,38 & 7,73 & 2,10 & 0,64 & 2,74 \\
\hline CV (\%) & 11,97 & 10,38 & 9,92 & 4,87 & 39,16 & 13,11 & 24,87 & 14,28 \\
\hline
\end{tabular}

* Significativo a 0,01de probabilidade.

Obteve-se a curva de regressão polinomial relacionando-se os níveis de salinidade aos valores médios das variáveis estudadas, o que permitiu a determinação dos efeitos da salinidade. As equações foram escolhidas com base na sua significância e no valor do coeficiente de determinação $\left(\mathrm{R}^{2}\right)$. A equação de maior grau utilizada foi do tipo quadrática, por se entender que os modelos cúbicos não explicam adequadamente os fenômenos biológicos.

$\mathrm{O}$ número de folhas foi reduzido à medida que se aumentou o nível salino da água da irrigação (Figura 1A). A equação que melhor representou a resposta das plantas foi do tipo linear $\left(\mathrm{R}^{2}=0,9759\right)$, sendo verificada uma redução de 48,7\% no maior nível salino, em comparação com a testemunha. Em condições de estresse salino, é comum ocorrerem alterações morfológicas e anatômicas nas plantas, refletindo-se redução de transpiração como alternativa para manter a absorção de água; uma dessas adaptações é a redução do número de folhas. Trabalhos realizados com outras culturas também demonstram o efeito da salinidade sobre o número de folhas. Oliveira et al. (2006) constataram redução no numero de folhas em mamoneira e Oliveira et al. (2007) na cultura do milhopipoca, híbrido 'Jade'.

Semelhante ao número de folhas, a área foliar foi reduzida linearmente com o incremento da salinidade (Figura 1B). No entanto observa-se um efeito mais representativo que no número de folhas, com uma redução de $65,90 \%$ obtido no tratamento mais salino em comparação com a testemunha. Percebe-se assim que a salinidade, além de reduzir o número de folhas, também reduz a área foliar individual. Segundo Tester \& Davenport (2003) este decréscimo da área foliar, possivelmente, está relacionado com um dos mecanismos de adaptação da planta ao estresse salino, diminuindo a superfície transpirante.

A diminuição da área foliar do feijão caupi sob condições de estresse salino é um mecanismo de extrema importância, uma vez que esta cultura é sensível à deficiência hídrica na zona radicular. A redução da área foliar sob tais condições é importante para manutenção de elevado potencial hídrico na planta, obtido através da diminuição na transpiração (DANTAS et al., 2003). A área foliar tem sua importância por ser um parâmetro indicativo da produtividade, pois o processo fotossintético depende da interceptação da energia luminosa e sua conversão em energia química, sendo este um processo que ocorre diretamente na folha, atuando na formação de carboidratos, que são alocados para os órgãos vegetativos e reprodutivos (BASTOS et al., 2002).

Observou-se uma redução na altura em cerca de 42,86\% nas plantas irrigadas com o maior nível salino (Figura 1C). Em trabalho realizado com algodão Martinez e Lauchli (1994) verificaram que, o efeito mais comum da 


\section{REVISTA VERDE DE AGROECOLOGIA E DESENVOLVIMENTO SUSTENTÁVEL GRUPO VERDE DE AGRICULTURA ALTERNATIVA (GVAA)}

salinidade sobre as plantas, de maneira geral, era a limitação do crescimento devido ao aumento da pressão osmótica do meio e a conseqüente redução da disponibilidade de água a ser consumida, afetando a divisão e o alongamento das células.

O diâmetro do caule foi reduzido linearmente com o aumento da salinidade da água de irrigação (Figura 1D), no entanto, foi à característica menos afetadas pelas condições salinas estudadas, de forma que a redução só

$1 \mathrm{~A}$

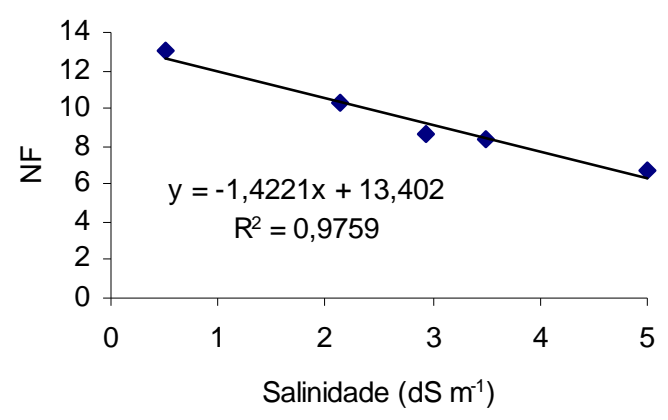

$1 C$

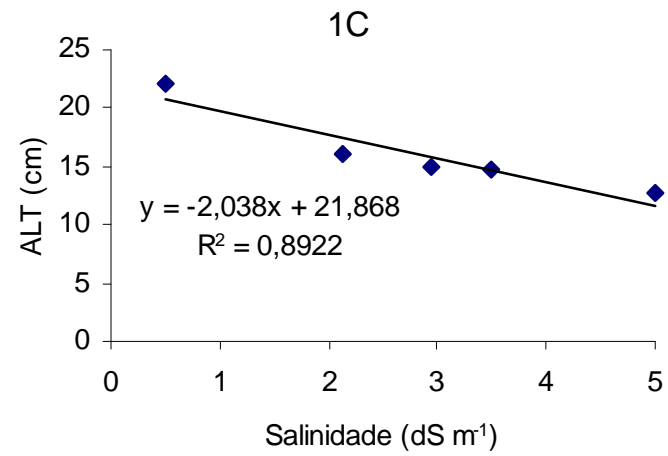

foi expressiva a partir da salinidade de 3,5 dS $\mathrm{m}^{-1}$, com uma redução 34,69\% em relação ao tratamento de menor salinidade. Segundo Morales et al. (2001), nem todas as partes da planta são igualmente afetadas pela salinidade, bem como, a adaptação ao estresse salino varia entre espécies e em um mesmo genótipo pode variar entre estádios fenológicos.
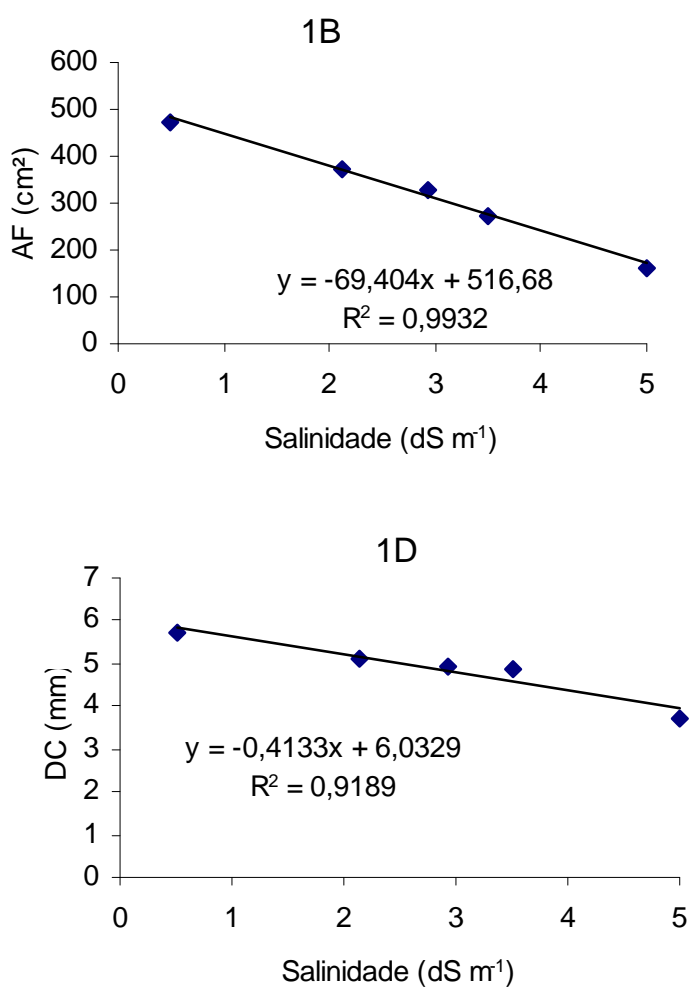

Figura 1. Número de folhas (1A) área foliar (1B), altura (1C) e diâmetro do caule (1D) de plantas de caupi submetidas à irrigação com água de diferentes salinidades. Mossoró, UFERSA, 2007.

O número de nódulos foi a variável mais afetada pela salinidade da água utilizada na irrigação (Figura 2A). A equação que melhor representa a resposta da planta nessa variável é do tipo potencial $\left(\mathrm{R}^{2}=0,7912\right)$, sendo encontrada uma redução de $79,3 \%$ já no segundo nível salino estudado (2,13 dS m $\left.\mathrm{m}^{-1}\right)$, reduzindo em 98,71\% na maior salinidade. Essa redução drástica pode ser em conseqüência do aumento da salinidade do solo (Figura 2B). Vasconcelos et al. (1987) também observaram expressiva redução da nodulação do feijão caupi cultivado em solos com diferentes níveis de salinidade, afetando, conseqüentemente, o desenvolvimento das plantas. A salinidade do extrato de saturação de solo aumentou linearmente de acordo com a salinidade da água de irrigação aplicadas nos diferentes tratamentos (Figura 2B). Desta forma, o uso de água na irrigação, enquanto contribui de maneira significativa para o aumento da produtividade, em determinadas situações, sobretudo em zonas de clima árido e semi-árido, pode resultar em acúmulo do teor de sais no solo. Resultados semelhantes são encontrados na literatura, como nos trabalhos desenvolvidos por Medeiros et al. (2002).

A matéria seca da parte aérea (Figura 2C) e das raízes (Figura 2D) decresceram linearmente à medida que se aumentou a salinidade da água. Para a MSPA, verificou-se uma redução expressiva a partir o segundo nível salino (2,13 dS $\mathrm{m}^{-1}$ ), diminuindo em 22,60\% em relação ao tratamento testemunha, no entanto a maior redução foi encontrada maior nível salino, com uma diminuição de 66,94\% (Figura 2C). Na MSR essa diminuição começou a ser mais expressiva a partir do nível salino 2,95 dS $\mathrm{m}^{-1}$, no entanto no maior nível, o efeito foi mais expressivo que na MSPA, com uma redução de 76,14\% em relação ao tratamento menos salino. Semelhante às matérias secas da parte aérea e das raízes, a matéria seca total também respondeu 


\section{REVISTA VERDE DE AGROECOLOGIA E DESENVOLVIMENTO SUSTENTÁVEL GRUPO VERDE DE AGRICULTURA ALTERNATIVA (GVAA)}

negativamente ao aumento da salinidade, com uma redução de 69,10\% em relação ao tratamento testemunha. Souza et al. (2007) estudaram o efeito da salinidade no caupi, cv. Pitiúba, e também encontraram resposta semelhante no acúmulo de matéria seca, concordando com os resultados obtidos por Dantas et al. (2003). Como observado em muitos casos, a redução no crescimento de glicófitas, incluindo-se o feijão-de-corda, parece se ajustar melhor a um modelo linear, depois de determinado valor limite de concentração de sais no meio (AYERS \& WESTCOT, 1999).

Analisando a relação MSPA/MSR observa-se que o sistema radicular foi mais afetado que a parte aérea, sendo o efeito mais representativo nas plantas que foram irrigadas com a água de maior nível salino (Figura 2F), resultados estes que corroboram aqueles encontrados por Souza et al. (2007). Moya et al. (1999), sugerem que a elevada redução no crescimento da raiz diminui a extração de íons potencialmente tóxicos do solo e favorecem a aclimatação da planta ao estresse salino, mas, outros estudos demonstraram maior crescimento do sistema radicular, em relação ao da parte aérea, em plantas submetidas a diferentes estresses abióticos (hídrico, salino e nutricional) e isto parece resultar em melhor exploração da umidade do solo e de nutrientes, o
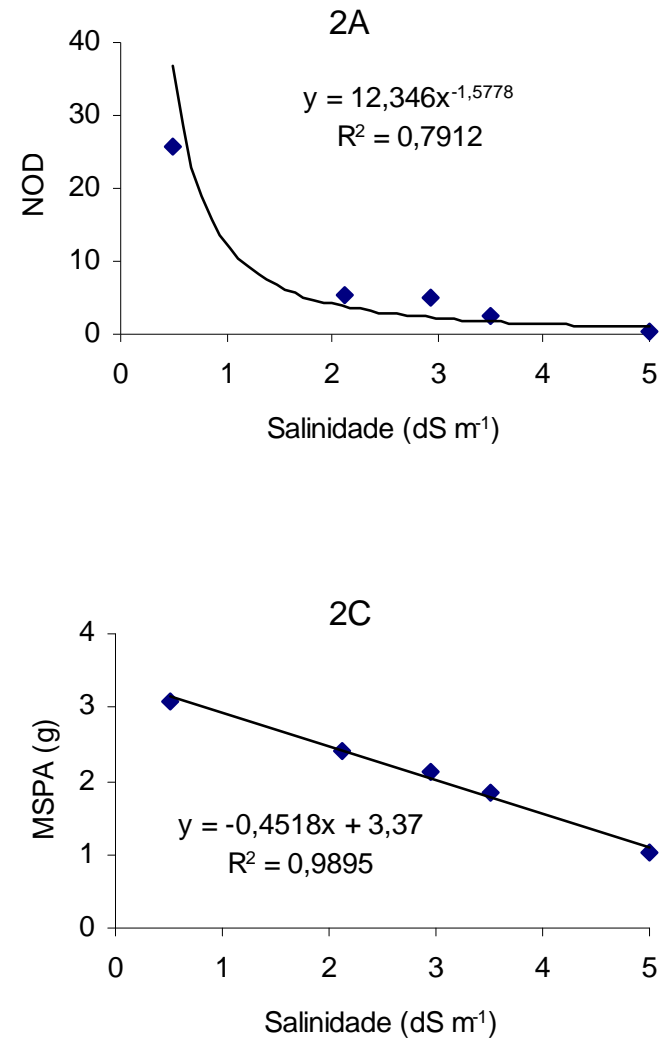

que favorece o crescimento sob condições adversas (SILVA et al., 2003).

O efeito da salinidade na relação MSPA/MSR é variável nas diferentes espécies estudadas. Gurgel et al (2003) avaliaram o efeito da salinidade da água de irrigação sobre os índices fisiológicos na aceroleira e verificaram que a salinidade prejudicou mais o sistema radicular que a parte aérea e esta última é menos afetada que a fitomassa seca total. No entanto, dados da literatura sugerem que, em milho, as raízes parecem suportar melhor a salinidade que a parte aérea, fenômeno este que pode estar associado a um ajustamento osmótico mais rápido e a uma perda de turgor mais lenta das raízes, quando comparadas com a parte aérea. Izzo et al. (1993) verificaram diminuição na razão parte aérea/raiz de plântulas de milho, com o incremento do estresse salino. Segundo Shannon et al. (1997), as raízes são diretamente expostas aos ambientes salinos, mas seu crescimento é menos afetado que a parte aérea, aumentando assim a relação MSR/MSPA. Correia et al. (2005) estudando os efeitos da salinidade em plântulas de arroz, verificaram que à medida que se elevou o nível salino, aumentaram também os valores da MSR/MSPA, principalmente no maior nível de CEa, em função de a parte aérea ter sido mais afetada pelos tratamentos salinos do que as raízes, o que denota sua maior sensibilidade aos sais.

2B
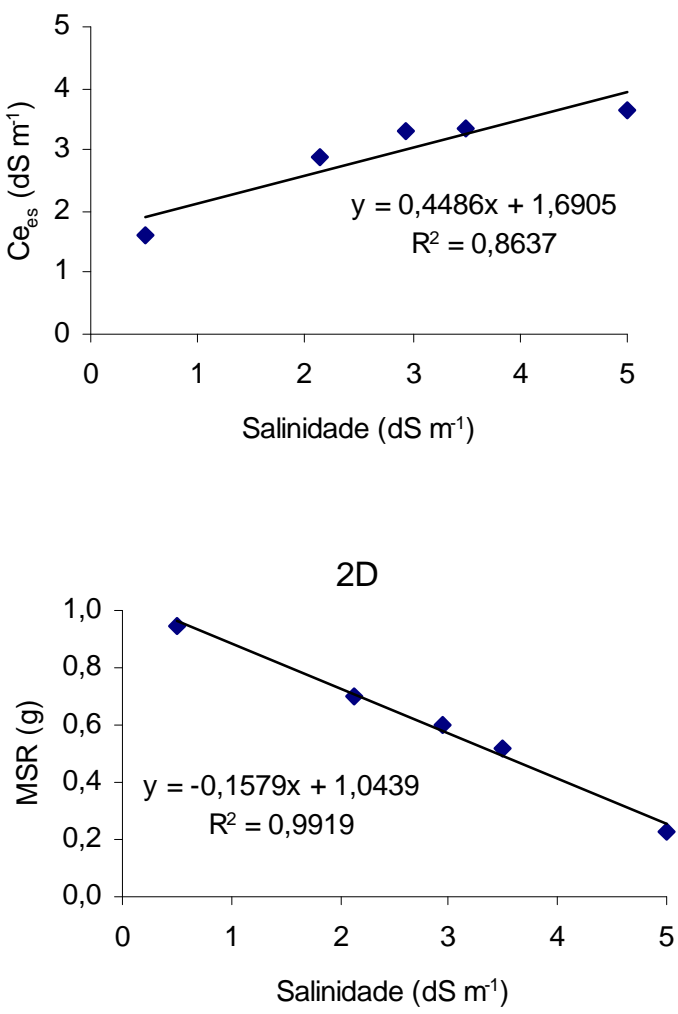


\section{REVISTA VERDE DE AGROECOLOGIA E DESENVOLVIMENTO SUSTENTÁVEL GRUPO VERDE DE AGRICULTURA ALTERNATIVA (GVAA)}
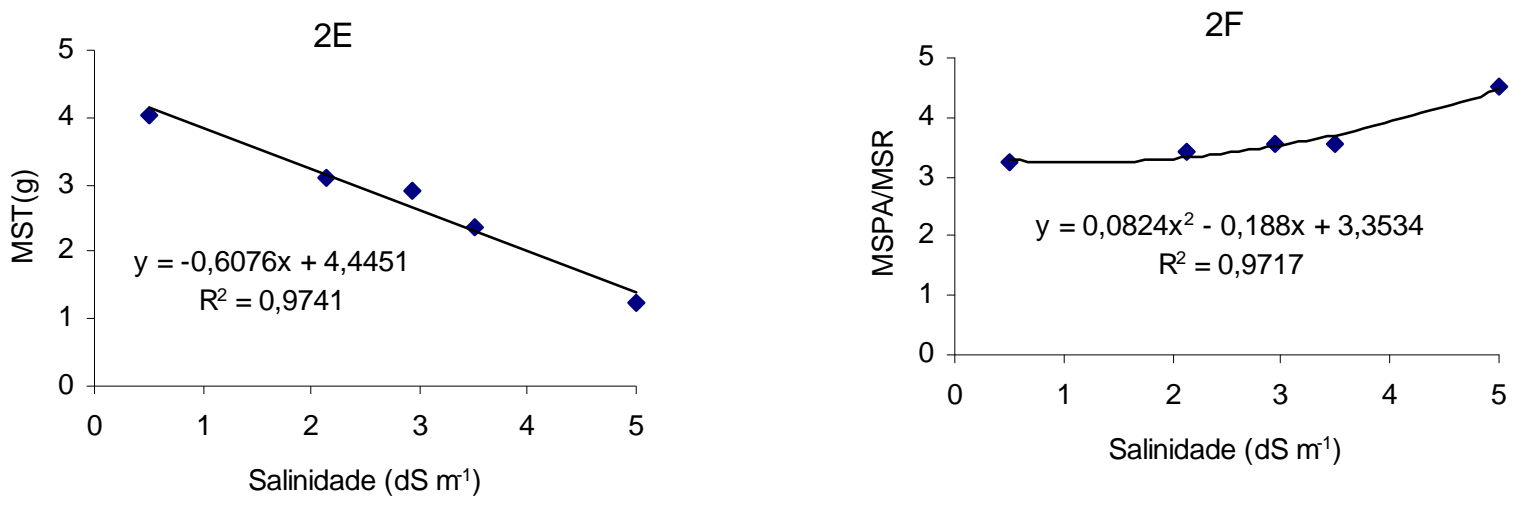

Figura 1. Número de nódulos (2A), salinidade do extrato de saturação do solo (2B), matéria seca da parte aérea (2C), matéria seca das raízes (2D), matéria seca total (2E) e relação MSPA/MSR (2F) de plantas de caupi submetidas à irrigação com água de diferentes salinidades. Mossoró, UFERSA, 2007.

Com relação à partição de matéria seca nas plantas de caupi, pode-se verificar que a matéria seca da parte aérea contribui em media com $77,37 \%$, sendo essa porcentagem aumentada com o incremento da salinidade, em contrapartida o sistema radicular foi mais afetado pela salinidade que a parte aérea (Tabela 2). Analisando a distribuição de MSPA, observa-se que a matéria seca das folhas representa em média 61,24\%, não sendo, no entanto, influenciada pelos níveis salinos aplicados. O conhecimento do partimento de forma adequada de assimilados pode contribuir para melhorar a produtividade das culturas por meio do incremento na produção de biomassa total favorecendo a transferência de assimilados para as partes colhidas da planta

Tabela 2. Partição de fotoassimilados em plantas de feijão caupi submetido à irrigação com água de diferentes níveis salinos. Mossoró, UFERSA, 2007.

\begin{tabular}{|c|c|c|c|c|c|}
\hline \multirow{2}{*}{$\begin{array}{c}\text { Salinidade } \\
\left(\mathrm{dS} \mathrm{m}^{-1}\right)\end{array}$} & \multirow{2}{*}{$\begin{array}{c}\text { MST } \\
(\mathrm{g})\end{array}$} & \multicolumn{2}{|c|}{-------------- MST -------------- } & \multicolumn{2}{|c|}{---------- MSPA ---------- } \\
\hline & & MSR (\%) & MSPA (\%) & MSFO (\%) & MSC (\%) \\
\hline 0,50 & 4,04 & 23,51 & 76,49 & 58,58 & 41,42 \\
\hline 2,13 & 3,10 & 22,68 & 77,32 & 61,32 & 38,68 \\
\hline 2,94 & 2,92 & 20,57 & 73,09 & 61,61 & 38,39 \\
\hline 3,50 & 2,38 & 21,86 & 78,14 & 62,42 & 37,58 \\
\hline 5,00 & 1,25 & 18,16 & 81,84 & 62,25 & 37,75 \\
\hline Média & $\begin{array}{c}--- \\
\end{array}$ & 21,36 & 77,37 & 61,24 & 38,76 \\
\hline
\end{tabular}

Também foi observado nesse estudo que o nível mais elevado de estresse salino reduziu a partição de matéria seca para as raízes e aumentando a da parte aérea tendo o aumento sido observado principalmente nas folhas (Tabela 2). Resultados semelhantes foram encontrados por Souza et al. (2007). As alterações na distribuição percentual da matéria seca provocadas pelo estresse salino são condizentes com o fato de que a salinidade, além de reduzir a produção de biomassa pode também alterar a partição de fotoassimilados entre as diferentes partes das plantas (SILVA, 2003).

\section{CONCLUSÕES}

A salinidade influenciou linearmente no crescimento vegetativo do feijão caupi, sendo todas as características analisadas reduzidas com o aumento da salinidade. As características mais afetadas pelo maior nível salino foram área foliar (65,90\%), matéria seca da parte aérea (66,94\%) e matéria seca das raízes (76,14\%).

A presença de nódulos nas raízes foi afetada drasticamente pela salinidade, com uma redução de $98,71 \%$ no maior nível.

A matéria seca total acumulada pelas plantas de caupi é distribuída em 22,5\% para a matéria seca das raízes e $77,5 \%$ da matéria seca da parte aérea, desta, $61,2 \%$ e $38 \%$ são distribuídas para matéria seca das folhas e do caule respectivamente.

\section{REFERENCIAS BIBLIOGRÁFICAS}




\section{REVISTA VERDE DE AGROECOLOGIA E DESENVOLVIMENTO SUSTENTÁVEL GRUPO VERDE DE AGRICULTURA ALTERNATIVA (GVAA)}

AYERS, R.S.; WESTCOT, D.W. A qualidade da água na agricultura. Campina Grande, UFPB, 1991. 153p.

BASTOS, E.A.; RODRIGUES, B.H.N.; ANDRADE JÚNIOR, A.S.; CARDOSO, M.J. Parâmetros de crescimento do feijão caupi sob diferentes regimes hídricos. Engenharia Agrícola, Jaboticabal, v.22, n.1, p.43-50, 2002.

CARMO FILHO, F. do; OLIVEIRA, O.F. de. Mossoró: um município do semi-árido nordestino, caracterização climática e aspecto florístico. Mossoró: ESAM, 1995. 62p. (Coleção Mossoroense, série B).

CORREIA, K.G.; FERNANDES, P.D.; GHEYI, H.R.; GURGEL, M.T.; RODRIGUES, L.N. Crescimento do amendoinzeiro irrigado com águas salinas. Revista Brasileira de Engenharia Agrícola e Ambiental, Campina Grande, v.9, (Suplemento), p.81-85, 2005.

DANTAS, J.P.; FERREIRA, M.M.M.; MARINHO, F.J.L.; NUNES, M.S.A.; QUEIROZ, M.F.; SANTOS, P.T.A. Efeito do estresse salino sobre a germinação e produção de sementes de caupi. Agropecuária Técnica, Areia, v.24, n.2, p.119-130, 2003.

DANTAS, J.P.; MARINHO, F. J. L.; FERREIRA, M.M.M.; AMORIM,M.S.N.; ANDRADE, S.I.O.; SALES, A.L. Avaliação de genótipos de caupi sob salinidade. Revista Brasileira de Engenharia Agrícola e Ambiental, Campina Grande, v.6, n.3, p.425-430, 2002.

GURGEL, M. T.; FERNANDES,P. D.; GHEYI, H. R.; SANTOS, F. J.; BEZERRA, I. L.; NOBRE, R. G. Índices fisiológicos e de crescimento de um porta-enxerto de aceroleira sob estresse salino. Revista Brasileira de Engenharia Agrícola e Ambiental, Campina Grande, v.7, n.3, p.451-456, 2003.

HOLANDA, J. P.; AMORIM, J.R.A. Qualidade de água para irrigação. In: GHEYI, H.R.; QUEIROZ, J.E.; MEDEIROS, J.M. (ed.) Manejo e controle da salinidade na agricultura irrigada. Campina Grande: UFPB-SBEA, 1997. p.137-169.

IZZO, R.; SCAGNOZZI, A.; BELLIGNO, A.; NAVARIIZZO, F. Influence of $\mathrm{NaCl}$ treatment on $\mathrm{Ca}, \mathrm{K}$ and $\mathrm{Na}$ interrelations in maize shoots. In: FRAGOSO, M.A.C.; BEUSICHEM, M.L. (Ed.) Optimization of plant nutrition. Netherlands: Kluwer Academic Publishers, 1993, p.577-582.

MARTINEZ, V.; LAUCHLI, A. Salt-induced of phosphate-leptake in plants of cotton. New phitol, Cambridge, v. 126, n. 4, p. 609-614, 1994.

MEDEIROS, J.F. DE.; GHEYI, H.R. Manejo do sistema solo-água-planta em solos afetados por sais. In: GHEYI, H.R.; QUEIROZ, J.E.; MEDEIROS, J.F. de (eds.). Manejo e controle da salinidade na agricultura irrigada. Campina Grande: UFPB/SBEA, 1997. Cap. 8, p. 239-284.

MEDEIROS. J.F.; CRUCIANI, D.E.; FOLEGATTI, M.V.; MIRANDA, N.O. Tolerância do pimentão à salinidade sob condições de cultivo protegido Engenharia Agrícola, Jaboticabal, v.22, n.2, p.200-210, 2002.

MORALES, M.A.; OLMOS, E.; TORRECILLAS, A.; ALARCON, J.J. Differences in water relations, leaf ion accumulation and excretion rates between cultivated and wild species of Limonium sp. grown in conditions of saline stress. Flora, Jena, v.196, n.5, p.345-352, 2001.

MOYA, J.L.; PRIMO-MILLO, E.; TALON, M. Morphological factors determining salt tolerance in citrus seedlings: the shoot to root ratio modulates passive root uptake of chloride ions and their accumulation in leaves. Plant, Cell and Environment, Logan, v.22, n.11, p.1425-1433, 1999.

OLIVEIRA, F.A.; MEDEIROS, J.F.; OLIVEIRA, M.K.T.; LIMA, C.J.G.S.; GALVÃO. D.C. desenvolvimento inicial do milho-pipoca 'Jade' irrigado com água de diferentes níveis de salinidade. Revista Verde de Agroecologia e Agricultura Sustentável, Mossoró, v.2, n.1, p.45-52, 2007

OLIVEIRA, M. K. T.; OLIVEIRA, F.A.; MEDEIROS, J. F.; LIMA, C. J. G. S.; GUIMARÃES, I. P. Efeito de diferentes teores de esterco bovino e íveis de salinidade no crescimento inicial da mamoneira (Ricinus communis). Revista Verde de Agroecologia e Agricultura Sustentável, Mossoró, v.1. n.1, p.68-74, 2006.

RHOADES, J.P.; KANDIAH, A.; MASHALI, A.M. Uso de águas salinas na produção agrícola. Campina Grande: UFPB, 2000. 117p. 
SANTANA, M.J.; CARVALHO, J.A.; ANDRADE, M.J.B.; SILVA, E.L. Desenvolvimento do feijoeiro (Phaseolus vulgaris L. cv. ESAL 686) sob irrigação com água salina. Irriga, Botucatu, v.8, n.1, p.29-36, 2003.

SHANNON, M.C. The effects of salinity on cellular and biochemical processes associated with salt tolerance in tropical plants. In: Proceedings in plant stress in the tropical environment Davenport T.L. Harrington; H.M. (ed.). Kailu-Kona: University of Florida, 1992, p.56-63.

SILVA J.V.; LACERDA, C.F.; COSTA, P.H.A.; ENÉAS-FILHO, J.; GOMES-FILHO, E.; PRISCO, J.T. Physiological responses of $\mathrm{NaCl}$ stressed cowpea plants grown in nutrient solution supplemented with $\mathrm{CaCl} 2$. Brazilian Journal of Plant Physiology, Campinas, v.15, n.2, p.99-105, 2003.

SOUSA, C.H.C.; LACERDA, C.F.; SOUSA, A.E.C.; ARRAES, F.D.D.; TORRES, F.R.G.; OLIVEIRA, M.I.B.; SOUZA, A.O.G. Produção de biomassa de plantas de sorgo, feijão-de-corda e algodão submetidos ao estresse salino. In: CONGRESSO BRASILEIRO DE
IRRIGAÇÃO E DRENAGEM, 17, Mossoró. Anais... Mossoró: ABID, 2007. (CD-ROM)

SOUSA, R.A.; LACERDA, C.F.; AMARO FILHO, J.; HERNANDEZ, F.F.F. Crescimento e nutrição mineral do feijão-de-corda em função da salinidade e da composição iônica da água de irrigação. Revista Brasileira de Ciências Agrárias. Recife, v.2, n.1, p.75-82, 2007

TESTER, M.; DAVENPORT, R. $\mathrm{Na}^{+}$tolerance and $\mathrm{Na}^{+}$ transport in higher plants. Annals of Botany, Oxford, v.91, p.503-527, 2003.

VASCONCELOS, I., ALVES, J.F. \& LIMA, I.T.

Nodulação do feijão-de-corda, Vigna sinensis (L) Savi, ao longo do ciclo cultural da planta. Ciência Agronômica, Fortaleza, v.6, n.1/2, p.11-15, 1976.

VASCONCELOS, I.; MENDES FILHO, P.F.; ALMEIDA, R.T. Nodulação e desenvolvimento do feijãode-corda, Vigna unguiculata (L.) Walp., em solos com diferentes nÍveis de salinidade. Ciência Agronômica, Fortaleza, v.18, n.1, p.125-130, 1987. 